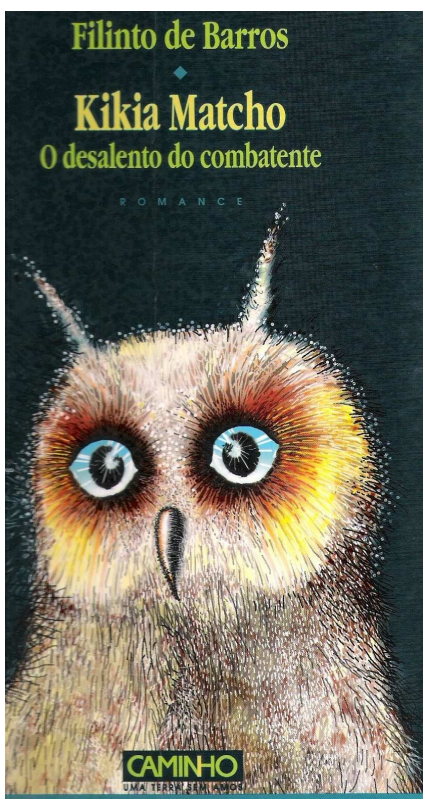

\title{
Kikia Matcho. O desalento do combatente, de Filinto de Barros
}

Jorge Otinta ${ }^{1}$

Ler o romance Kikia Matcho é acompanhar, através do cenário bissauense, as peripécias do combatente, NDinguy, cujo nome já evoca, no crioulo bissauguineense, solidão ou abandono de alguém. Neste caso, o sentimento é provocado pela sensação de impotência de NDinguy diante do esvair-se da causa revolucionária em função do crescimento da corrupção. Delineiam-se, assim, as possiveis aproximações entre a realidade ficcional e a concreta, na medida em que um retrato contundente e brutal da Guiné-Bissau nos anos pós-independência emerge sabiamente desenhado na trama romanesca. É esta, segundo me parece, a ilação que se tira após a leitura deste romance, editado em Lisboa, em 1999, pela Editora Caminho.

Em Kikia Matcho, cujo título remete à coruja, ave considerada agourenta, o leitor acompanha as peripécias em Bissau, no Bairro de Tchon di Pepel, do combatente que se distanciou dos seus camaradas por discordar dos rumos da revolução e que, por isso mesmo, amarga a infima pensão que recebe do Estado por meio do Estatuto de Combatente da Liberdade da Pátria, com a qual tenta sobreviver. Desse modo, para reconstruir sua vida, a partir dos cacos resgatados, pouco a pouco, obtém o consolo nas noites saudosistas à base do vinho de caju,

1 Doutorando em Estudos Comparados de Literaturas de Língua Portuguesa (FFLCH/USP). Projeto de pesquisa: "A representação literária do intelectual nos romances Mayombe e Kikia Matcho - O desalento do combatente". 
na pensão da Mana Tchambú, a Tia Burin Mudjo, onde procura um solo fértil para a sua própria história, e, por que não, a do próprio país?

Interessante a figura da Mana Tchambú, mulher guerreira, trabalhadora, a qual no seu trabalho de ganha pão, vai conhecendo a vida dos seus clientes assiduos na pensão, pois era ela a que os ouvia e os escutava e, simultaneamente, os consolava com sua companhia e seus conselhos nas longas e intermináveis sessões de bebedeira pa mata flema, para atenuar a dureza da nova realidade. A seguir a passagem que melhor ilustra isto:

Mana Tchambú conhecia a história de cada um, desiludidos, débeis mentais, que encontraram no álcool o sentido, não da vida, mas da resignação. No passado tiveram algum valor, jogaram algum papel no turbilhão da sociedade emergente no continente. A maior parte tinha acreditado em ideias, valores, etc., tudo quimeras! Comandantes, comissários políticos, embaixadores, Comissários de Estado, milícias, comandos africanos, uma mistura carnavalesca, como carnavalesca tem sido a vida deste pequeno país! (p.66-7)

O herói, talvez o único nesta Bissau dos anos 80 e 90, foi capaz de inventar um passado, como seus próprios companheiros inventaram novos nomes (Infali Sissé, nome que um dos personagens da trama adotou na guerra e com o qual se apresenta aos outros), portanto, novas identidades para driblar as agruras da vida.

É possível afirmar que o romance dispõe-se a dialogar com a realidade na medida em que a própria experiência do autor Filinto de Barros, como intelectual e como guerrilheiro, parece contribuir para as cenas que se organizam ao longo do romance. Nesse sentido, é válido lembrar a participação do escritor como líder da ala da juventude do PAIGC durante a luta pela independência; como mobilizador dos jovens para a necessidade premente de aderirem, em massa, a causa revolucionária; e, finalmente, como embaixador em Lisboa e Ministro de várias pastas, entre as quais destacamos a dos Recursos Naturais e Indústria e a das Finanças. 
Todas essas atividades contribuíram, sem dúvida, para que o escritor tenha conseguido pôr a seco o regime visto de dentro e de fora; mas, sobretudo, recriado no âmbito da escrita ficcional, o tecido social guineense tão bem retratado no dilema campo/cidade, modernidade/tradição, naquilo que foi o percurso do protagonista do romance e dos personagens que permeiam toda a trama romanesca.

O desencanto do protagonista NDinguy com os problemas por que estava a passar o país, especialmente nos anos 80, com os falhanços dos projetos do Programa de Ajustamento Estrutural (PAE) ${ }^{2}$, na transição de um sistema colonial inócuo e violento para o sistema de democracia revolucionária, como denominava o $\mathrm{PAIGC}^{3}$ traz ao combatente uma significativa sensação de perda dos ideais libertários que consolidaram a guerra de libertação nacional. Além disso, a frustração por ver seu lar desfazer-se com a imigração, primeiro, de sua sobrinha Joana para Lisboa em busca de melhores condições de vida; e, em seguida, de seu sobrinho Antônio Benaf - intelectual desempregado

2 PAE - Programa de Ajustamento Estrutural visava segundo as partes signatárias, o governo guineense $\mathrm{e}$ as instituições de Bretton Woods, ao desenvolvimento da Guiné-Bissau, como uma das metas a atingir com a estabilização da economia e melhoria nas condições de vida da população. Mas, a bem da verdade, este ajustamento foi imposto ao governo de Bissau como solução para os problemas estruturais existentes: déficit público, economia de subsistência, má governação, uma certa desorganização dos tecidos social e político guineenses e as quase precárias condições das infraestruturas. Porém, o FMI e BM acabaram com todas as reformas estruturais que se propunham para a área econômica. As propostas do FMI e do BM, tendendo para a liberalização econômica e estímulo dos mercados em detrimento da intervenção estatal, traduzem-se em medidas de redução de taxas de utilização dos serviços públicos, supressão de subsídios, redimensionamento da administração pública, cortes, congelamentos salariais e privatizações. Os resultados destas reformas foram catastróficos, porquanto não só não melhoraram o déficit orçamental, como os efeitos negativos das restrições orçamentais sobre o bem-estar, geraram um ambiente de promiscuidade social e o agravamento do sector informal como estratégia de sobrevivência. Como resultado destas medidas, o cidadão guineense viu-se perante um Estado fragilizado que, por um lado, teve que lidar com as restrições à obtenção de empréstimos e ajudas; e, por outro lado, os políticos guineenses, mesmo perante este dilema, não se coibiram do exercício da corrupção, do clientelismo e do neopatrimonialismo, como estratégia para o enriquecimento fácil. cf.: IMBALI, Faustino (Coord.). Os efeitos socioeconômicos do Programa de Ajustamento Estrutural na Guiné-Bissau. Bissau, INEP, 1993. e também MONTEIRO, Isaac (Coord.). O Programa de Ajustamento Estrutural: análise dos efeitos socioeconômicos. Bissau, INEP, 1996.

3 PAIGC - Partido Africano da Independência da Guiné e Cabo Verde: partido liderado por Amílcar Cabral que conduziu a independência da Guiné-Bissau (24.09.1973) e a de Cabo Verde (05.07.1975). 
cujo distanciamento das tradições locais justificava-se pelo fato de ter vivenciado ao longo de sua formação universitária o sistema marxistaleninista na Sofia, Bulgaria.

Um exemplo dessa tensão ocorre no romance quando da cerimônia fúnebre de NDinguy, em que seu sobrinho Benaf vê-se diante do dilema de realizar a cerimônia de acordo com a tradição do tio, do próprio Benaf e, portanto, de toda a sua família. Desnuda-se, então, o conflito de Benaf com as tradições locais, já que por ter sido educado de acordo com os valores da tradição ocidental, tenta subtrair-se da tarefa a que, por tradição, lhe era destinado. A seguir, a passagem:

A cerimônia tinha mesmo que ser realizada para acalmar a família. Acontece que o velhote [Papai, companeiro de armas de $\mathrm{N}$ Dinguy] era a única pessoa capaz de levar o processo [da condução da cerimônia] para frente. Logo, acompanhar o velho Papai passou a ser a tarefa do jovem licenciado Benaf. Que maçada! O velho era até interessante, simpático, mas os temas eram sempre os mesmos, a fazer lembrar o outro lado da consciência, precisamente o lado que [Benaf] estava interessado em eliminar (grifo meu, p.145).

Quanto à linguagem, trata-se de um estilo simples e direto, até mesmo na forma jornalística com que inicia o romance: “... O Comitê do Partido [leia-se PAIGC] do Sector Autónomo da Cidade de Bissau apresenta à família enlutada as suas mais sentidas condolências..." (p.9). Além disso, a passagem aponta para um certo lamento, fruto da tensão dialética que mobiliza a sociedade guineense após a independência quando se fazia necessário traçar os novos rumos do país.

Portanto, as figuras bissauguineenses do romance de Filinto de Barros, quer sejam gente simples do povo, quer sejam pessoas da liderança deste mesmo povo, representam simbolicamente os perfis de uma sociedade heterogênea e em constante conflito de auto-aceitação. Evidencia-se, assim, o complexo processo das grandes transformações sociais ocorridas nesta cidade de Bissau do pós-colonialismo, figurada no cotidiano e na relação entre as classes sociais outrora diferenciadas; 
mas que, na atual situação social da quase-miséria do país, irmana e acolhe a cínica relação de o kampo kinti, kau di firma ka ten (a situação está difícil para todos) de ontem.

Ao narrar, o autor do romance realiza um dissecar do microcosmo da Guiné-Bissau em que a licitude e a ilicitude dos atos dos homens confundem-se com a vontade coletiva de manter acesa a esperança, mesmo que as condições socioeconômicas não o possibilitem. Pois as mazelas sociais das populações, o choque entre as diversas tradições etnoculturais do país, a multiplicidade das crenças e confissões religiosas podem ter contribuído, sem dúvida, para a difícil paz social a que tanto se almeja; aliada aos frequentes sobressaltos gerados por conflitos político-militares.

Embora a representação do desencanto incorpore-se ao tecido romanesco, parece-me triunfar o princípio esperança, segundo o qual a palavra de ordem é teimar e ousar, porque o amanhã será melhor - ou pelo menos o será para os filhos. Uma crença que se revela realizável na práxis cotidiana do viver. É este crer no devir que Filinto de Barros ressalta na epígrafe da obra: "Kikia Matcho é um pequeno exercício de ficção. Nem história, nem sociologia, nem etnologia, nem política, tãosomente uma abordagem que se pretende dinâmica do processo de sintese sociocultural de um Povo" (p.7)

Se um romance é como mundo que se constrói, então pode-se dizer que o autor torna-se narrador de uma História da Guiné-Bissau que (re)conhece, porque a viveu e a construiu, quer como militante do partido libertador, PAIGC, quer como intelectual, servindo ao país em vários momentos de sua história recente. Em suma, não obstante aos sucessivos problemas guineenses, tais como infraestrutura falhada, governo(s) falhado(s), o autor nos testemunha a incrivel capacidade de resistência do povo, a qual parece florir teimosamente a cada dia que passa, apesar do(s) governo(s), ou devido a ele(s), supera-se sempre a força épica e cultural do povo.

BARROS, Filinto de. Kikia Matcho. $O$ desalento do combatente. Lisboa: Caminho, 1999. 